\title{
DC electrical conduction in strontium vanadium borate glasses
}

\author{
Arunkumar V. BANAGAR ${ }^{1}$, Prashant Kumar M. ${ }^{2, *}$, N. NAGARAJA ${ }^{1}$, AnAND Tipperudra ${ }^{1}$, \\ SANGAMESH JAKATI ${ }^{3}$ \\ ${ }^{1}$ Department of Physics, RYM's Engineering College, Ballari, Karnataka, India \\ ${ }^{2}$ Government College (Autonomous), Kalaburagi, Karnataka, India \\ ${ }^{3}$ Department of Physics Proudhadevaraya Institute of Technology, Hosapete, Karnataka, India
}

\begin{abstract}
A series of borate glasses with the composition $\mathrm{x}(\mathrm{SrO}) \cdot(50-\mathrm{x}) \mathrm{V}_{2} \mathrm{O}_{5} \cdot 0.5\left(\mathrm{~B}_{2} \mathrm{O}_{3}\right)$ where $\mathrm{x}=0,0.1,0.2,0.3$ and 0.4 were prepared by melt-quenching technique. The non-crystalline nature of the glasses has been established by XRD studies. Room temperature density and DC electrical conductivity of the samples were investigated in the temperature range of $300 \mathrm{~K}$ to $443 \mathrm{~K}$. The molar volume and oxygen packing density (OPD) were estimated. The results show that the density, molar volume and OPD decrease with the increasing of SrO mole fraction. The DC electrical conductivity data has been analyzed in the light of Mott's small polaron hopping (SPH) model and the activation energies were estimated. The conductivity was observed to rapidly fall and activation energy was found to increase when $\mathrm{SrO}$ was incorporated into the glass network. This may indicate that $\mathrm{Sr}^{+}$ions have not contributed to the total conductivity and the observed conductivity may be of polaronic type only, which is due to the hopping of electrons between multivalent states of vanadium. Various small polaron hopping parameters such as small polaron radius, $r_{p}$, effective dielectric constant, $\epsilon_{\mathrm{p}}$, polaron band width, J, optical phonon frequency, $v_{\mathrm{o}}$, small polaron coupling constant, $\gamma_{\mathrm{p}}$, density of states at Fermi level, $\mathrm{N}\left(\mathrm{E}_{\mathrm{F}}\right)$ were estimated and discussed.
\end{abstract}

Keywords: borate glasses; transition metal ions; alkaline earth ions, electrical conductivity; Mott's small polaron hopping

\section{Introduction}

Borate glasses containing alkali and transition meal ions (TMI) were found to have novel applications in development of solid state batteries, solid state laser devices and optical fibres in the field of communications [1]. Both TMIs and alkali ions contained in borate glasses can exhibit mixed electrical conductivity and hence, they have found a number of technological applications. These properties depend mainly on different valance states of doped TMI in the glass network [2]. Some glasses doped with single alkali and TMI not only show mixed electronic and ionic conductivity but also they exhibit changeover of conduction mechanism from electronic to ionic or vice versa at a particular composition. The glasses showing such type of interesting behavior are potential candidates for the applications in solid state batteries as electrodes.

*E-mail: pacificmg@gmail.com
Electrical conductivity in glasses containing TMI was explained by the hopping of electrons between low valence bands to high valence bands of TMI which is known as small polaron hopping [3-5].

Borate glasses doped with $\mathrm{Na}^{+} / \mathrm{Li}^{+} / \mathrm{Ag}^{+}$ are called the fast ion conductors (FIC) and they are potential candidates for use in solid state batteries $[6,7]$. This kind of electrical conduction helps them to be used as potential candidates for solid state electrolytes in electrochemical devices, such as batteries, smart windows and chemical sensors [8].

Nagaraja et al. [9] studied the electrical conductivity in $\mathrm{Li}_{2} \mathrm{O}-\mathrm{CoO}-\mathrm{B}_{2} \mathrm{O}_{3}$ glasses and found a changeover in conduction mechanism from electronic to ionic. S. Sindhu et al. [11] studied the structural, optical, physical and electrical properties of $\mathrm{V}_{2} \mathrm{O}_{5}-\mathrm{SrO}-\mathrm{B}_{2} \mathrm{O}_{3}$ glasses. They found that their DC conductivity increased and activation energy decreased with the addition of $\mathrm{V}_{2} \mathrm{O}_{5}$. 
P. Vasantharani et al. [12] carried out the studies on structural and elastic properties of strontium doped manganese borate glasses and reported that the increase in $\mathrm{SrO}$ concentration leads to the increase in the value of density, ultrasonic velocities and various elastic moduli.

Keeping in view the mentioned facts, to the best of our knowledge, not sufficient work has been done on physical, electrical conductivity properties and estimation of various polaron related parameters of borate glasses containing $\mathrm{V}_{2} \mathrm{O}_{5}$ and $\mathrm{SrO}$ with the chemical composition: $\mathrm{x}(\mathrm{SrO}) \cdot(50-\mathrm{x})$ $\mathrm{V}_{2} \mathrm{O}_{5} \cdot 0.5\left(\mathrm{~B}_{2} \mathrm{O}_{3}\right)$, where $\mathrm{x}=0,0.1,0.2,0.3,0.4$. These glass samples were coded as BVS1, BVS2, BVS3, BVS4 and BVS5 respectively.

\section{Experimental}

To synthesize the glass samples with a general formula of $x(\mathrm{SrO}) \cdot(50-\mathrm{x}) \mathrm{V}_{2} \mathrm{O}_{5} \cdot 0.5\left(\mathrm{~B}_{2} \mathrm{O}_{3}\right)$, meltquenching method has been employed. Analytical grade chemicals of $\mathrm{H}_{3} \mathrm{BO}_{3}$, SrO and $\mathrm{V}_{2} \mathrm{O}_{5}$ (HIMEDIA, purity $>99.95$ ) were used for the preparation of the glass samples. The chemical quantities in required weight ratios were taken into silica crucibles and the composition was thoroughly mixed in order to obtain homogeneity. These silica crucibles were taken into an electrical muffle furnace and melted between the temperatures ranging from $1423 \mathrm{~K}$ to $1473 \mathrm{~K}$ to get different glass compositions. After confirming that the melt was transparent, it was suddenly quenched at room temperature by pouring it onto a stainless steel plate and covering it with another stainless steel plate. The collected samples were of different size and shape and they were then annealed at $473 \mathrm{~K}$ in order to remove thermal strain, if any, in them. In order to confirm their non-crystalline nature, the as-prepared samples were subjected to XRD study. Room temperature density of these glass samples was determined by Archimedes principle, taking toluene as an immersion liquid using following expression [13].

$$
D=\left(\frac{W_{\text {air }}}{W_{\text {air }}-W_{L}}\right) D_{L} \quad\left[\mathrm{~g} / \mathrm{cm}^{3}\right]
$$

where, $\mathrm{W}_{\text {air }}$ is the weight of the glass samples in air, $\mathrm{W}_{\mathrm{L}}$ is the weight of the sample in toluene and $\mathrm{D}_{\mathrm{L}}$ is the density of toluene $(0.87 \mathrm{~g} / \mathrm{mol})$. The error in density was found to be less than $3 \%$. The molar volume $\left(\mathrm{V}_{\mathrm{m}}\right)$ of the prepared glass samples was determined by the expression [14]:

$$
V_{m}=\frac{\sum x_{i} M_{i}}{\rho}
$$

where: $\mathrm{M}_{\mathrm{i}}$ is the molecular weight of glass calculated by multiplying $x_{i}$ times the molecular weight of various constituents and $\rho$ is density of the glass.

The arrangement of oxygen atoms in the oxide glasses is determined from the oxygen packing density (OPD). The oxygen packing density can be calculated from the relation [15].

$$
O P D=\frac{1000(O)}{V_{m}}
$$

where $\mathrm{O}$ represents the number of oxygens present in the glass.

The prepared glass samples were polished and cut into suitable rectangular shape of the size ranging from $0.66 \mathrm{~cm}^{2}$ to $1.06 \mathrm{~cm}^{2}$ in cross-sectional area and from $1.31 \mathrm{~mm}$ to $1.92 \mathrm{~mm}$ in thickness. Silver electrodes were painted on two major surfaces of the sample. By using two-probe method, the electrical conductivity of the present samples has been measured in the temperature ranging from $300 \mathrm{~K}$ to $443 \mathrm{~K}$. The voltage and current were measured by digital voltmeter and digital picometer (SES Instruments). Temperature of the samples was measured by a chromel alumel thermocouple. The conductivity of the glass samples was calculated using $\sigma=\frac{1}{\rho}$ where $\rho$ is the resistivity given by $\rho=\frac{R \cdot A}{d}$, where, $R$ is the resistance, $A$ is the cross-sectional area and $\mathrm{d}$ is the thickness of the glass sample.

\section{Results and discussion}

\subsection{XRD}

Fig. 1 shows the XRD pattern of BVS2 glass sample. No peak has been observed which confirms the non-crystalline nature of the samples. In the figure, a large bump can be observed at $25^{\circ}$. This is 


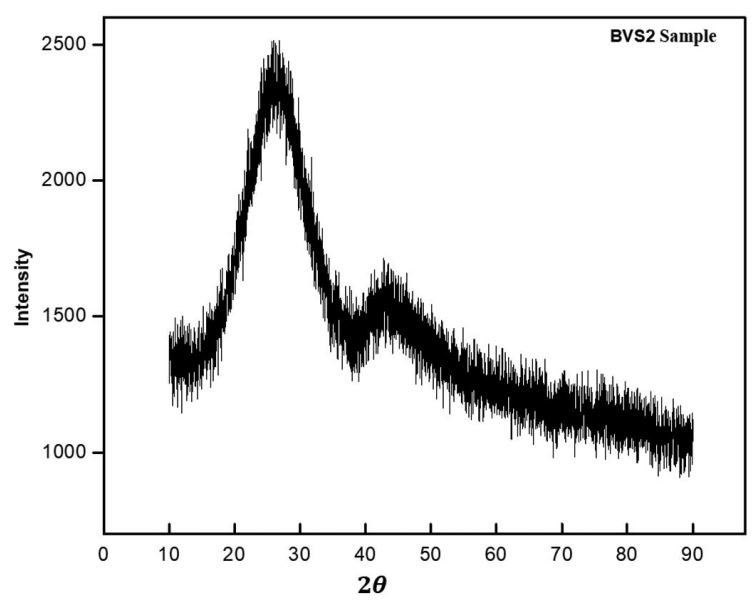

Fig. 1. XRD pattern of BVS2 glass

ascribed to the scattering of X-rays in many directions owing to the amorphous structure of the sample. Further at $45^{\circ}$, the observed small but widely distributed bump may be related to the second order diffraction maxima. Similar nature was observed for the remaining glass samples.

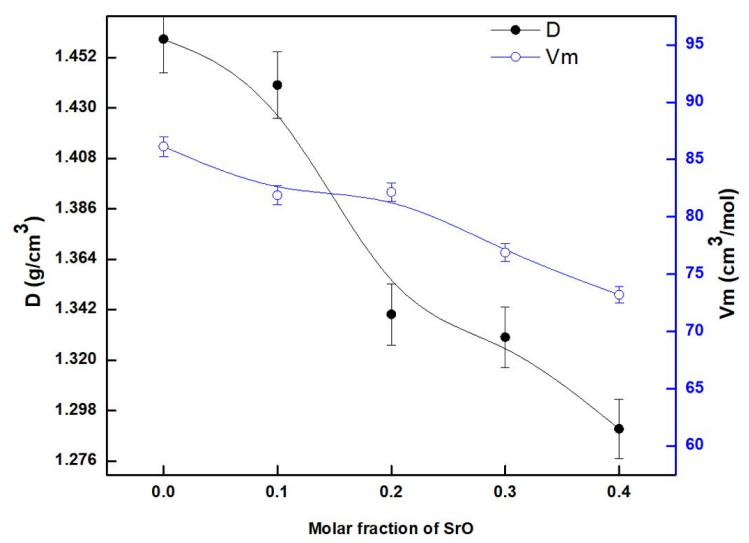

Fig. 2. Plot of density (D), molar volume $\left(\mathrm{V}_{\mathrm{m}}\right)$ as a function of molar SrO fraction in BVS glasses.

\subsection{Density and molar volume}

The density (D) and molar volume $\left(\mathrm{V}_{\mathrm{m}}\right)$ in the present glasses varied from $1.29 \mathrm{~g} / \mathrm{cm}^{3}$ to $1.46 \mathrm{~g} / \mathrm{cm}^{3}$ and $73.214 \mathrm{~cm}^{3} / \mathrm{mol}$ to $86.130 \mathrm{~cm}^{3} / \mathrm{mol}$ (Table 1). The variation of density (D) and molar volume $\left(\mathrm{V}_{\mathrm{m}}\right)$ in the present glasses has been depicted in Fig. 2. From the figure it can be observed that both density and molar volume in the present glasses decreased with an increase in the concentration of $\mathrm{SrO}$ and attained minimum at $\mathrm{x}=0.4$. It has been reported that the incorporation of one mole of $\mathrm{SrO}$ into $\mathrm{B}_{2} \mathrm{O}_{3}$ matrix converts two $\mathrm{BO}_{3}$ units into two $\mathrm{BO}_{4}$ units [16]. The conversion of $\mathrm{BO}_{3}$ into $\mathrm{BO}_{4}$ structural units increases the number of non-bridging oxygens (NBOs). The increase in the number of NBOs may lead to randomization of the glass structure and also reduction in both the density and molar volume. This type of behavior is in agreement with the literature reported for other borate based glasses [17-20]. Fig. 3 illustrates the variation of molar volume and OPD with molar fraction of SrO. In the present work, it has been observed that both the molar volume and OPD decrease with an increase in $\mathrm{SrO}$ content. Similar kind of variation has been reported [17-20].

Various physical properties such as transition metal ion concentration, $\mathrm{N}$, the mean ion spacing, $R$, and Debye temperature, $\theta_{D}$, were estimated for the reported glass system (Table 1). These values are comparable with the values reported for many borate based glasses [21-23].

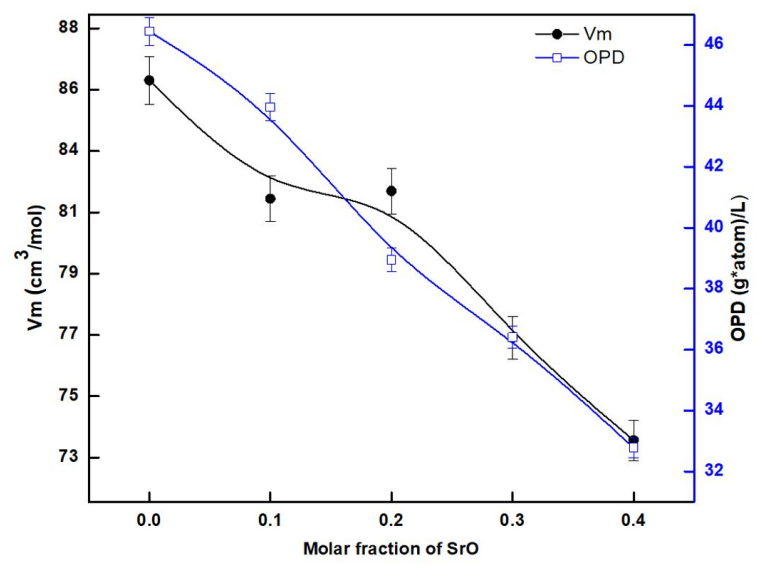

Fig. 3. Variation of molar volume and OPD with molar fraction of $\mathrm{SrO}$.

\subsection{DC conductivity}

The measured DC electrical conductivity in the present glasses was found to be in the range of $1.496 \times 10^{-5} \Omega^{-1} \mathrm{~m}^{-1}$ to $3.976 \times 10^{-11} \Omega^{-1} \mathrm{~m}^{-1}$ in the temperature range of $300 \mathrm{~K}$ to $443 \mathrm{~K}$. These values of DC conductivity are comparable with 
Table 1. Physical properties of BVS glasses

\begin{tabular}{|c|c|c|c|c|c|c|c|c|c|}
\hline \multirow{2}{*}{ Glass code } & \multicolumn{3}{|c|}{ Composition of glass } & \multirow{2}{*}{$\begin{array}{c}\mathrm{D} \\
{\left[\mathrm{g} / \mathrm{cm}^{3}\right]}\end{array}$} & \multirow{2}{*}{$\begin{array}{c}\mathrm{Vm} \\
{\left[\mathrm{cm}^{3} / \mathrm{mol}\right]}\end{array}$} & \multirow{2}{*}{$\begin{array}{c}\mathrm{N} \times 10^{21} \\
{\left[\mathrm{~cm}^{-3}\right]}\end{array}$} & \multirow{2}{*}{$\begin{array}{c}\mathrm{R} \\
{[\mathrm{nm}]}\end{array}$} & \multirow{2}{*}{$\begin{array}{c}\theta_{\mathrm{D}} \\
{[\mathrm{K}]}\end{array}$} & \multirow{2}{*}{$\begin{array}{c}\text { OPD } \\
{[\mathrm{g} \mathrm{atm} / \mathrm{L}]}\end{array}$} \\
\hline & $0.5\left(\mathrm{~B}_{2} \mathrm{O}_{3}\right.$ & $(0.5-x) \mathrm{V}_{2} \mathrm{O}_{5}$ & $\mathrm{x}(\mathrm{SrO})$ & & & & & & \\
\hline BVS1 & 0.5 & 0.5 & 0 & 1.46 & 86.130 & 4.834 & 5.924 & 946 & 46.441 \\
\hline BVS2 & 0.5 & 0.4 & 0.1 & 1.44 & 81.892 & 3.814 & 6.411 & 786 & 43.961 \\
\hline BVS3 & 0.5 & 0.3 & 0.2 & 1.34 & 82.163 & 2.662 & 7.227 & 606 & 38.947 \\
\hline BVS4 & 0.5 & 0.2 & 0.3 & 1.33 & 76.896 & 1.761 & 8.294 & 806 & 36.413 \\
\hline BVS5 & 0.5 & 0.1 & 0.4 & 1.29 & 73.214 & 8.542 & 10.556 & 646 & 32.781 \\
\hline
\end{tabular}

the values reported for other borate based glasses doped with alkaline earth oxide and transition metal ions [24, 25]. The behavior of conductivity $(\sigma)$ versus temperature $(\mathrm{K})$ is plotted in Fig. 4 for BVS2 glass. From the figure it can be seen that the electrical conductivity $(\sigma)$ increases with an increase in temperature, indicating that the present glasses are semiconducting in nature.

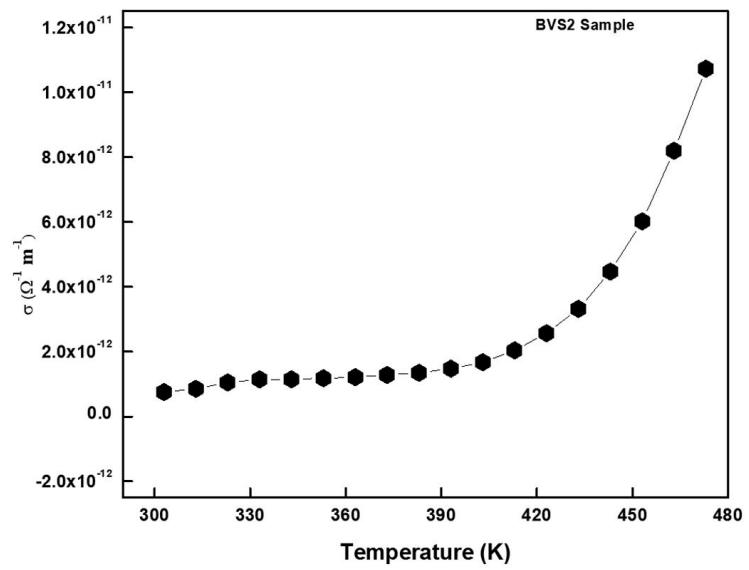

Fig. 4. Plot of conductivity $(\sigma)$ versus temperature $[\mathrm{K}]$

As per the Mott's small polaron hopping theory [26], the $\ln (\sigma \mathrm{T})$ versus $(1000 / \mathrm{T})$ plots were plotted and shown in Fig. 5. The curves were found to be linear in high temperature regime ( $\left.\mathrm{T}>\theta_{\mathrm{D}} / 2\right)$ and non-linear in low temperature regime $\left(T<\theta_{\mathrm{D}} / 2\right)$. The linear variation of conductivity at high temperatures is characteristic of small-polaron hopping conduction mechanism [26]. The nature of the graph is similar to that of the reported borate glasses doped with TMI [27, 28].

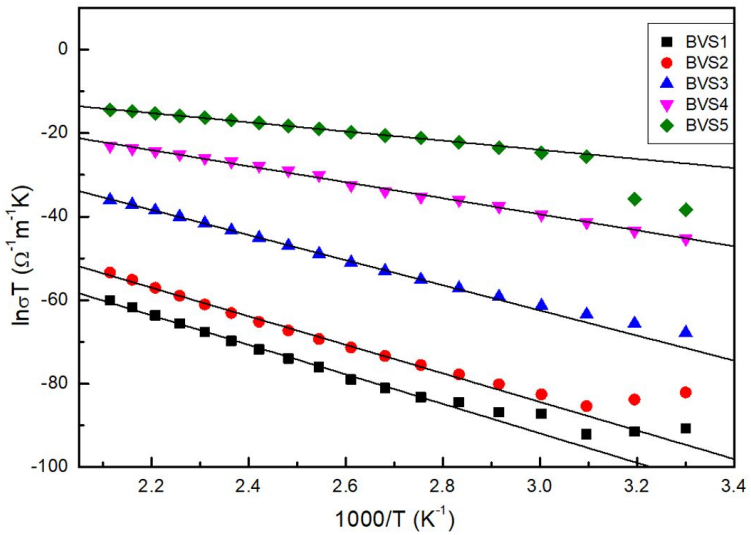

Fig. 5. Plot of $\ln (\sigma \mathrm{T})$ versus $(1000 / \mathrm{T})$ for BSV glasses; the lines are least square fit made to the data.

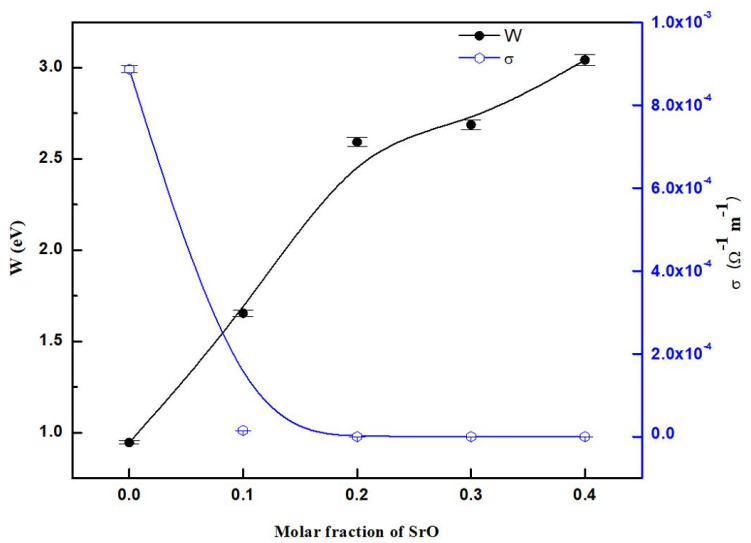

Fig. 6. Plot of activation energy, W, and conductivity $\sigma_{\mathrm{dc}}$ at $443 \mathrm{~K}$ as a function of molar fraction $\mathrm{SrO}$.

The linear lines were fit to the data in Fig. 5 corresponding to the high temperature region. From the linear fit, the $\mathrm{R}$ square value or chi square value was determined from the best fit linear curve for all the glass samples readings. The $\mathrm{R}$ value was 
found to be in the range from 0.99413 to 0.99734 for all the glass samples. The slope of linear fits was determined from the plots, and activation energy $W$ was calculated. The activation energies in the present glasses were found to be in the range of $0.945 \mathrm{eV}$ to $3.042 \mathrm{eV}$ (Table 2). These values are comparable with the reported values for similar kind of glasses [29, 30].

Fig. 6 shows the variation of conductivity $\sigma$ at $443 \mathrm{~K}$ and activation energy, $\mathrm{W}$, as a function of mole fraction of $\mathrm{SrO}$ for BVS glasses. From the figure, it was observed that the electrical conductivity decreased and activation energy increased with an increase in $\mathrm{SrO}$ mole fraction. The conductivity is observed to be high in the absence of $\mathrm{SrO}$ (BVS1). With the addition of SrO, the conductivity was found to decrease which is in agreement with the similar alkali doped silicate glasses [31]. The decrease in conductivity with the increase in $\mathrm{SrO}$ concentration may be attributed to the fact that the $\mathrm{B}_{2} \mathrm{O}_{3}$ is a network primarily consisting of a random three-dimensional network of six membered boroxol rings [32] and the incorporation of one molecule of $\mathrm{SrO}$ into the $\mathrm{B}_{2} \mathrm{O}_{3}$ matrix, converts two $\mathrm{BO}_{3}$ units into two $\mathrm{BO}_{4}$ units [33]. In the present glass system, the addition of $\mathrm{SrO}$ causes the formation of NBOs which makes the structure more rigid and thereby causes a decrease in its conductivity [34]. The determined activation energy in the present glasses containing 0 and 0.1 mole fractions of $\mathrm{SrO}$ are much lower compared to those of the glasses having 0.2 and more mole fractions of $\mathrm{SrO}$. The incorporation of $\mathrm{SrO}$ into the present glass system may have hindered the electronic motion and hence, the decrease in electrical conductivity was observed. The higher values of activation energies above 0.2 mole fractions of $\mathrm{SrO}$ may be attributed to the structural changes occurring in the glass network and also more pronounced hindrance offered by $\mathrm{SrO}$ ions to electrical conduction. In the prepared glass system, the increase in activation energy from $0.945 \mathrm{eV}$ to $3.042 \mathrm{eV}$ was reflected in that the electrical conduction was hindered by $\mathrm{SrO}$.

In the present glass systems, the conductivity of BVS1 is found to be very high compared to all other glass samples (Fig. 6). It can be observed

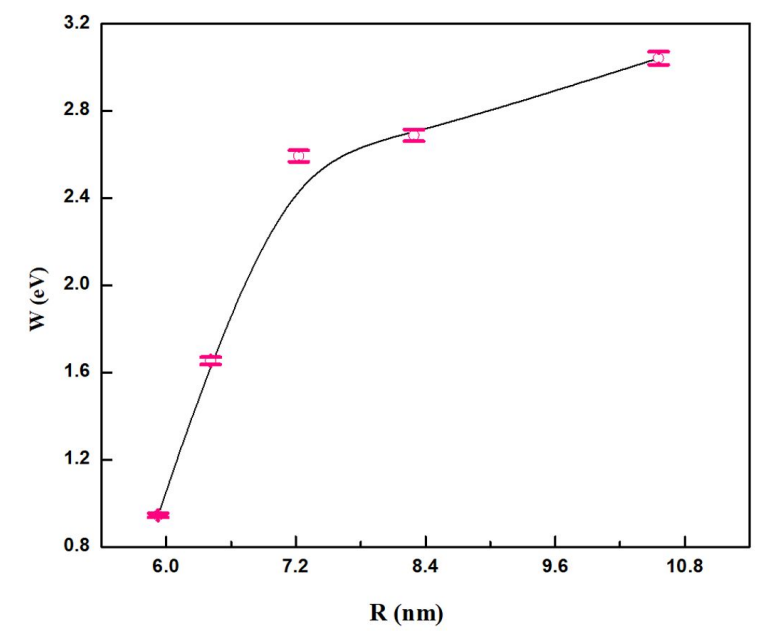

Fig. 7. Effect of the mean distance $\mathrm{R}$ on activation energy $\mathrm{W}$ for multivalent states of vanadium ions.

that the conductivity suddenly falls as soon as the $\mathrm{SrO}$ is brought into the glass network. Similarly, the activation energy is found to increase rapidly for $\mathrm{SrO}$ doped glass samples. This type of variation in conductivity and activation energy indicates that $\mathrm{Sr}^{+}$ions are not at all contributing to the total conductivity. Hence, the observed conductivity may be electronic alone which is due to the hopping of electrons between multivalent states of vanadium $[35,36]$.

It has been reported that the DC conductivity in many TMI doped borate and other glasses is controlled by electron hopping that depends upon the value of $\mathrm{R}[37,38]$. From Table 2 it can be seen that with the increase in concentration of $\mathrm{SrO}$ both the mean distance, $\mathrm{R}$, and activation energy, $\mathrm{W}$, increase. The variation of $\mathrm{W}$ with respect to $\mathrm{R}$ is illustrated in Fig. 7. Similar results have been observed in other TMI doped borate glasses [37, 38]. Based on these results one may establish that the conduction mechanism in the present glass system is due to hopping of electrons between $\mathrm{V}^{4+}$ and $\mathrm{V}^{5+}$ ions. These results are in accordance with the reported articles $[39,40]$.

\subsection{Small polaron hopping parameters}

For the present glass system, various small polaron hopping parameters, such as small polaron radius, $r_{p}$, effective dielectric constant, $\epsilon_{\mathrm{p}}$, polaron 
Table 2. Various polaron related parameters for BVS glasses

\begin{tabular}{|c|c|c|c|c|c|c|c|c|c|}
\hline $\begin{array}{l}\text { Sample } \\
\text { Code }\end{array}$ & $\begin{array}{c}\mathrm{W} \\
{[\mathrm{eV}]}\end{array}$ & $\begin{array}{c}\sigma \text { at } 443 \mathrm{~K} \\
{\left[\Omega^{-1} \cdot \mathrm{m}^{-1}\right]}\end{array}$ & $\begin{array}{c}\mathrm{r}_{\mathrm{p}} \\
{[\mathrm{nm}]}\end{array}$ & $\epsilon_{\mathrm{P}}$ & $\begin{array}{l}\mathrm{W}_{\mathrm{H}} \\
{[\mathrm{eV}]}\end{array}$ & $\begin{array}{c}\mathrm{J} \\
{[\mathrm{eV}]}\end{array}$ & $\begin{array}{c}v_{\mathrm{o}} \\
\times 10^{13} \\
{[\mathrm{~Hz}]}\end{array}$ & $\gamma_{\mathrm{p}}$ & $\begin{array}{c}\mathrm{N}\left(\mathrm{E}_{\mathrm{F}}\right) \\
\times 10^{20} \\
{\left[\mathrm{eV}^{-1} \cdot \mathrm{m}^{-3}\right]}\end{array}$ \\
\hline BVS1 & 0.945 & $8.865 \times 10^{-4}$ & 2.384 & 1.111 & 0.565 & 0.008 & 1.971 & 13.86 & 1.216 \\
\hline BVS2 & 1.653 & $1.496 \times 10^{-5}$ & 2.580 & 0.587 & 0.988 & 0.006 & 1.637 & 29.17 & 5.488 \\
\hline BVS3 & 2.593 & $2.013 \times 10^{-8}$ & 2.908 & 0.332 & 1.550 & 0.004 & 1.262 & 59.35 & 2.442 \\
\hline BVS4 & 2.688 & $4.476 \times 10^{-12}$ & 3.337 & 0.279 & 1.606 & 0.002 & 1.679 & 46.26 & 1.559 \\
\hline BVS5 & 3.042 & $3.97 \times 10^{-11}$ & 4.248 & 0.194 & 1.818 & 0.001 & 1.346 & 65.32 & 6.679 \\
\hline
\end{tabular}

band width, J, optical phonon frequency, $v_{\mathrm{o}}$, small polaron coupling constant, $\gamma_{\mathrm{p}}$, density of states at Fermi level, $\mathrm{N}\left(\mathrm{E}_{\mathrm{F}}\right)$ were estimated and tabulated in Table 2. The theoretical method of calculating the polaron hopping energy $\mathrm{W}_{\mathrm{H}}$ is given by [41]:

$$
W_{H}=\frac{W_{P}}{2}=\frac{e^{2}}{4 \varepsilon_{p}}\left(\frac{1}{r_{p}}-\frac{1}{R}\right)
$$

where $\mathrm{W}_{\mathrm{P}}$ is the polaron binding energy, $\epsilon_{\mathrm{p}}$ is the effective dielectric constant which can be determined from the following relation [42]:

$$
\varepsilon_{p}=\frac{e^{2}}{4 W r_{p}}
$$

where, $r_{p}$ is the small polaron radius which is estimated from the relation [43]:

$$
r_{p}=\left(\frac{1}{2}\right)\left(\frac{\pi}{6 N}\right)^{\frac{1}{3}}
$$

where $\mathrm{N}$ is transition metal ion concentration which can be calculated from the expression [43]:

$$
N=2\left(\frac{\rho M f_{T M I}}{M W_{T M I}}\right) N_{A}
$$

where $\rho$ is the density of glass, $\mathrm{Mf}_{\mathrm{TMI}}$ is mol\% of TMI, $M W_{T M I}$ is molecular weight of TMI and $\mathrm{N}_{\mathrm{A}}$ is the Avogadro number. The density of states at Fermi level, $\mathrm{N}\left(\mathrm{E}_{\mathrm{F}}\right)$ can be estimated from the expression [44]:

$$
N\left(E_{F}\right)=\frac{3}{4 \pi R^{3} W}
$$

The estimated values of $\mathrm{N}\left(\mathrm{E}_{\mathrm{F}}\right)$ are of the order of $10^{20}$ for the present glass systems. These
$\mathrm{N}\left(\mathrm{E}_{\mathrm{F}}\right)$ values are in agreement with the cited values of many single and mixed alkali doped borate glasses [44-47]. The polaron coupling constant $\gamma_{p}$ is a measure of electron-phonon interaction which can be estimated by the equation [48]:

$$
\gamma_{p}=\frac{2 W_{H}}{h v_{0}}
$$

where $v_{0}$ is the optical phonon frequency that can be calculated from the equation, $v_{0}=\frac{\theta_{\mathrm{DK}_{\mathrm{B}}}}{\mathrm{h}}$ where $h$ is the Planck constant $\theta_{D}=2 T_{D}$ is the Debye temperature and $\mathrm{T}_{\mathrm{D}}$ is the temperature at which the lines deviate from linearity in $\ln (\sigma \mathrm{T})$ vs. $(1 / \mathrm{T})$ plot.

According to SPH model, the polaron bandwidth $\mathrm{J}$ is given by

$$
J=J_{O} \exp (-\alpha R)
$$

where, $\mathrm{J}_{O}=\frac{\mathrm{W}_{\mathrm{H}_{\text {min }}}}{4}$ [49] and $\alpha$ is electron wave function decay constant.

The calculated values of $\mathbf{J}$ are tabulated in the Table 2. The condition for formation of small polaron is given by $J \leqslant \frac{\mathrm{W}_{\mathrm{H}}}{3}$ [50]. From Table 2, it is noted that the values of $\mathrm{J}$ are in the range of $0.001 \mathrm{eV}$ to $0.008 \mathrm{eV}$ for all glass samples, which indicates that the nature of conduction is non-adiabatic. The estimated value of $\gamma_{p}$ for the present glasses is 13.86 to 65.32 . Such high values of $\gamma_{\mathrm{p}}$ are the indication for a strong interaction between electrons and phonons [51]. As per our estimated values, it is observed that $\gamma_{\mathrm{p}}$ values are large and do not vary systematically with the molar fraction of SrO. This kind of variation of $\gamma_{p}$ may be attributed to the electrical conduction in high temperature regime to be due to non-adiabatic small polaron hopping between $\mathrm{V}^{4+}$ to $\mathrm{V}^{5+}$ ions. 


\section{Conclusions}

A series of borate glasses containing $\mathrm{V}_{2} \mathrm{O}_{5}$ and $\mathrm{SrO}$ were prepared by melt quenching technique with $\mathrm{SrO}$ molar fraction $\mathrm{x}=0,0.1,0.2,0.3$ and 0.4 . The non-crystalline nature of the samples was confirmed by XRD studies. The room temperature density, molar volume, OPD and temperature dependent DC electrical conductivity were investigated. The density and molar volume decreased with the increase in $\mathrm{SrO}$ content. This may be due to structural changes taking place in the glass network. The electrical conductivity was found to decrease and activation energy increased with the increase in $\mathrm{SrO}$ content. The conductivity was found to be the highest for $0 \mathrm{~mol} \%$ of $\mathrm{SrO}$ and it decreased continuously with further increase in $\mathrm{SrO} \mathrm{mol} \%$. The activation energy for the glass containing 0 to $0.1 \%$ mole fraction of $\mathrm{SrO}$ was lower than that of other glasses in the present series. This type of variation in conductivity and activation energy indicates that $\mathrm{Sr}^{+}$ions do not at all contribute to the total conductivity and the observed conductivity may be due to hopping of electrons alone between multivalent states of vanadium. The high temperature conductivity data has been analyzed in terms of Mott's small polaron hopping (SPH) model and various polaron related parameters have been estimated and discussed.

\section{References}

[1] M.M. El-Desoky, J. Non-Cryst. Solids, 351 (2005) 3139-3146.

[2] S.G. MotKe, S.P. Yawale, S.S. Yawale, Bull. Mater. Sci. 25 (1), (2002) 75.

[3] M.Nagaswa and H. Watanabe, 1971, UK Patent No. 1358930.

[4] R.A. Montani, M. Levy, J. L. Souquet., (1992) J. Non-Cryst. Solids, 149, 249.

[5] Aboutaleb And SAFI, J Chem. Eng. Process Technol 2016, 7:1

[6] P. Pacuta, R. Lungu, I. Ardelean., J.Mater.Sci. Mater, Electron., 21 (2010) 548-553.

[7] S. Rada, R. Chelcea, E. Culea, J. Mater.Sci, 45 (2010) 6025-6029.

[8] A. Al-Shahrani, A. Al-Hajru, M.M. ElDESOKY, Phys. B 364 (2005) 248

[9] N. Nagaraja, T. SANKarappa, M. Prashant KuMAR, J. Non-Cryst. Solids 354 (2008) 1503-1508.
[10] G. Srinivasa RaO, G. Thirumala Ral, B. SaIlaja, P. Narayana Murthy, N. Madhu, R.V.S.S.N. RaVikumar, Int. J. Adv. Res. Phys. Sci. 2 (2015) 41-45.

[11] S. Sindhu, S. Sanghi, A. Agarwal, VP Seth, N. KIsHORE, Spectrochim. Acta, Part A 64 (2006) 196-204.

[12] P. VASAntharani, S. NeElayathashi alias VICHITRA., J. App.Phy 9 (2017) 44-49.

[13] Safeya Ibrahim, Mohamed Mahmoud GomaA, HuSSEIN DARWISH, J. Adv. Ceramics 3(2) (2014) 155164.

[14] E Mansour, J. Non- Cryst. Solids 357 (2011) 13641369.

[15] V.C. Veeranna Gowda, Physica B., 426 (2013) 5864.

[16] V. Kundu, R.L. Dhiman, A.S. MaAn, D.R. Goyal, S. Arora, J. Optoelectr. Adv. Mater, 12 (12) (2010) 2373-2379.

[17] Y.C. Ratanakaran, A.V. Reddy, J. Non- Cryst. Solids, 277142 (2000)

[18] M.M. EI-Desoky, A. Al-Shahrani, Phy. B 383 (2006) 163-170.

[19] M.M. EI-Desoky, J. Non-Cryst. Solids, 351 (37-39) (2005) 3139-3146.

[20] S. Annamalai, R.P. Bhatta, I.L. PegG, B. Dutta, J. Non-Cryst. Solids 358 (2012) 1380.

[21] E. Mansour, G. El-Damrawi, S. El-Maksoud, Y. Moustafa, H. Doweidar, Phys. Chem. Glasses 43 (02) (2002) 80.

[22] Al-Shahrani, A. Al-Hajry, M.M. El-Desoky, Phys. Status Solidi (a) 200 (2) (2003) 378

[23] A.A. Bahgat, Y.M. ABou-Zeid, Phys. Chem. Glasses 42 (6) (2001) 361.

[24] S. Sindhu, S. Sanghi, A. Agrawal, V.P. Seth, N. KISHORE, Spectrochim. Acta part A 64 (2006) 196-204.

[25] V. Kundu, R.L. Dhiman, A.S. MaAn, D.R. Goyal, S. Arora, J. Optoelectr. Adv. Mater, 12 (12) (2010) 2373-2379.

[26] K.K. Som, B.K. Choudhuri, Phys. Rev. B 41 (3) (1990) 1581.

[27] N. NAgaraja, T. Sankarappa, M. Prashant KUMAR, J. Non-Cryst. Solids 354 (2008) 1503-1508.

[28] N.A. Eissa, A.G. Mostafa, I. Kashif, H.H. ElBahnasawy, E.K. AbDel-KhaleK, H.A. SAllam, Al- Azhar Univ. Eng. J. (AUEJ) 8 January (4) (2005).

[29] I.G. Austin, N.F. MotT, Adv. Phys. 18 (1969) 41.

[30] A.E. Owen, Prog. Ceram. Sci. (1963) 77.

[31] Alexander MN, OnORato PIK., Struck CW, ROZEN JR, TASKER GW, UHLMANN DR., J Non Cryst Solids. 1986; 79:137144.

[32] M.J. Gang, Y.J. Kim. S.J. Moon. S.J. Chung, D.J. CHA, New Phys. 28 (1988) 605 (In Korean, cited in PA, Abstract number 76547, 92 (1365) (1989) (6481).

[33] V. Kundu, R.L. Dhiman, A.S. MaAn, D.R. Goyal, S. Arora, J. Optoelectr. Adv. Mater, 12 (12) (2010) 2373-2379. 
[34] Rajesh Barde, Sandeep Waghuley, J. Chin. Adv. Mater. Soc., 2 (2014) 273-283.

[35] H. El MKami, B. Deroide, R. BAckov, J.V. Zanchetta, J. Phys. Chem. Solids., 61 (2000) 819826.

[36] M.K. El-Mansy, J. Mater. Chem. Phys., 56 (1998) 236.

[37] M.S. Al-Assiri, S.A. SAlem, M.M. El-Desoky, J. Phys. Chem. Solids, 67 (2006) 1873-1881.

[38] H.H. Qui. T. Ito, H. SaKata, Mater. Chem. Phys., 58 (1999) 1004.

[39] T. Suzuki, M. Hirano, H. Hosono, J. Appl.Phys., 91 (2002) 4149.

[40] M.M. El-Desoky, I. Kashif, Phys.Stat. Sol., 194 (2002) 89.

[41] M.J. Gang, Y.J. KIM. S.J. Moon. S.J. Chung, D.J. CHA, New Phys., 28 (1988) 605 (in Korean, cited in PA, Abstract number 76547, 92 (1365) (1989) (6481).

[42] M.M. EI-Desoky, J. Non-Cryst. Solids, 351 (37-39) (2005) 3139-3146.

[43] H. Hosono, K. Nomura, Y. Ogo, T. Uruga, T. KAmiYA, J. Non- Cryst. Solids., 354 (19-25) (2008) 2796.
[44] M.S. Al-Assiri, S.A. SALEM, M.M. El-Desoky, $J$ Phys. Chem. Solids, 67 (2006) 1873-1881

[45] N.F. MotT. E.A. DAVIS, Electronic processes in NonCrystalline Materials, Clarendon, Oxford, 1979.M.M. El-Desoky, J. Non-Cryst. Solids 351 (2005) 3139.

[46] M.M. El-Desoky, N.M. Tashtoush, M.H. Habib, J. Mater. Sci.: Mater. Electronics., 16 (2005) 533-539.

[47] D. Emin, T. Holstein, Ann. Phys., 53 (1969) 439520.

[48] M. M. El-Desoky, N. M. Tashtoush, M. H. HAвIB, J. Mater. Sci- Mater. Electron., 16 (2005) 533539.

[49] K. Sega, Y. Kuroda, H. SaKata, J. Mater. Sci., 33 (1998) 138.

[50] D. Emin, T. Holstein, Ann. Phys., 53 (1969) 439520.

[51] N.F. MotT, E.A. DAVIS, Electronic processes in NonCrystalline Materials, Clarendon, Oxford, 1979.

Received 2018-11-03 Accepted 2019-04-23 